\title{
Addendum: Morén, C.; Hernández, S.; Guitart-Mampel, M.; Garrabou, G. Mitochondrial Toxicity in Human Pregnancy: An Update on Clinical and Experimental Approaches in the Last 10 Years. Int. J. Environ. Res. Public Health 2014, 11, 9897-9918
}

\author{
Constanza Morén 1,2,*, Sandra Hernández ${ }^{2,3}$, Mariona Guitart-Mampel 1,2,* \\ and Glòria Garrabou 1,2 \\ 1 Muscle Research and Mitochondrial Function Laboratory, Cellex-IDIBAPS-Faculty of \\ Medicine-University of Barcelona, Internal Medicine Service-Hospital Clínic of Barcelona, \\ Barcelona 08036, Spain; garrabou@clinic.ub.es \\ 2 Centro de Investigación Biomédica en Red (CIBER) de Enfermedades Raras, CIBERER, \\ Valencia 46010, Spain; ashernan@clinic.ub.es \\ 3 Materno-Fetal Medicine Department, Clinical Institute of Gynaecology, Obstetrics and Neonatology, \\ Barcelona 08025, Spain \\ * Correspondence: cmoren1@clinic.ub.es (C.M.); mguitart@clinic.ub.es (M.G.-M.); \\ Tel.: +34-93-227-5400 (ext. 2907) (C.M.); Fax: +34-93-227-9365 (C.M.)
}

Academic Editor: Paul B. Tchounwou

Received: 20 October 2016; Accepted: 27 October 2016; Published: 8 November 2016

The authors wish to update the Acknowledgments Section in their paper published in the International Journal of Environmental Research and Public Health [1], doi:10.3390/ijerph110909897, website: http://www.mdpi.com/1660-4601/11/9/9897.

Acknowledgments: This work was supported by Fundación para la Investigación y la Prevención del SIDA en España [FIPSE 360745/09 and 360982/10]; Fundació Cellex, Fondo de Investigación Sanitaria [FIS 12/01199, PI13/01738 and PI13/01455]; Suports a Grups de Recerca de la Generalitat de Catalunya [SGR 2014/376] and CIBER de Enfermedades Raras (CIBERER, an initiative of ISCIII). We also wish to thank the valuable help of our laboratory and clinical staff (Ester Tobias, Marc Catalan, Ester Lozano, Francesc Cardellach and Josep Maria Grau), and Donna Pringle for language assistance. Besides the aforementioned acknowledgments for funding our work, this study has been granted by Instituto de Salud Carlos III through the project "PI12/01199" (Co-funded by the European Regional Development Fund (ERDF) "a way to build Europe").

Conflicts of Interest: The authors declare no conflict of interest.

\section{Reference}

1. Morén, C.; Hernández, S.; Guitart-Mampel, M.; Garrabou, G. Mitochondrial Toxicity in Human Pregnancy: An Update on Clinical and Experimental Approaches in the Last 10 Years. Int. J. Environ. Res. Public Health 2014, 11, 9897-9918. [CrossRef] [PubMed]

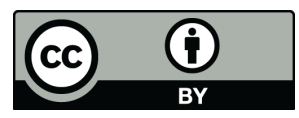

(C) 2016 by the authors; licensee MDPI, Basel, Switzerland. This article is an open access article distributed under the terms and conditions of the Creative Commons Attribution (CC-BY) license (http://creativecommons.org/licenses/by/4.0/). 